\title{
Prospects for Mobile Health in Pakistan and Other Developing Countries
}

\author{
Aqil Burney ${ }^{1,2}$, Zain Abbas ${ }^{1}$, Nadeem Mahmood ${ }^{1}$, Qamar-ul Arifeen ${ }^{1}$ \\ ${ }^{1}$ Department of Computer Science, University of Karachi, Karachi, Pakistan \\ ${ }^{2}$ Institute of Business Management, College of Computer Science and Information Systems, Karachi, Pakistan \\ Email: burney@uok.edu.pk, zain@uok.edu.pk,nmahmood@uok.edu.pk, arifeen@uok.edu.pk \\ Received March 10, 2013; revised April 21, 2013; accepted May 1, 2013
}

Copyright (C) 2013 Aqil Burney et al. This is an open access article distributed under the Creative Commons Attribution License, which permits unrestricted use, distribution, and reproduction in any medium, provided the original work is properly cited.

\begin{abstract}
Pakistan is a developing country with more than half of its population located in rural areas. These areas neither have sufficient health care facilities nor a strong infrastructure that can address the health needs of the people. The expansion of Information and Communication Technology (ICT) around the globe has set up an unprecedented opportunity for delivery of healthcare facilities and infrastructure in these rural areas of Pakistan as well as in other developing countries. Mobile Health (mHealth) - the provision of health care services through mobile telephony — will revolutionize the way health care is delivered. From messaging campaigns to remote monitoring, mobile technology will impact every aspect of health systems. This paper highlights the growth of ICT sector and status of health care facilities in the developing countries, and explores prospects of mHealth as a transformer for health systems and service delivery especially in the remote rural areas.
\end{abstract}

Keywords: Mobile Health; Telemedicine; eHealth; mHealth; ICT; Heath Care in Pakistan

\section{Introduction}

The use of Information and Communication Technologies in health care is generally referred as eHealth, telehealth or telemedicine. Simply put telemedicine is provisioning of healthcare services at a distance using ICT. eHealth not only refers to the role of ICT in healthcare, but also to a way of thinking, a state of mind, and a commitment to improve the standard of health care being provided worldwide by using the ICT industry [1]. eHealth is the intersection of Information Sciences, Computer Science, Information Technology and Healthcare. It deals with various approaches used in storage, retrieval, and transfer of information in healthcare and biomedicine. It includes computers as well as clinical guidelines, formal medical terminologies, and information and communication systems [2].

Telehealth is transforming the systems of care throughout the world. It provides greater access to medical facilities and consultation, as well as sharing knowledge, experience, and training. Leap-frogging over prior barriers, ICT also has the potential to offer greater access to these services in developing countries [3]. The use of telehealth must be put in context of the critical health needs in each country, communication infrastructure, and likelihood for sustainability. Furthermore, it should be aimed at improving the indigenous capacity in providing health services and blending into the country's health care system [4].

Telemedicine is primarily used to provide health care to the inaccessible and underprivileged areas. It has a strong affect in developing countries since it allows remote locations to get access to medical care and create local knowledge. It is more efficacious and have big influence especially in areas where experts are rare, distances are large and/or infrastructure is limited [5]. The history of telemedicine dates back to 1950 , when it was first used at the National Bureau of Standards, United States [6].

The rapid progress in ICT over the past few decades has brought about substantial advances in the quality of medical services provided to the patients. Developed countries are spending a lot of resources towards the integration of ICT with health care systems [2]. However, there are financial constraints in the developing countries that hamper their progress in telehealth [7]. They require technology transfer and capacity building sponsored by developed nations. Apart from financial constraints, the other important thing is the reforms in healthcare policy and a change of attitude towards eHealth [2]. 
The expansion of mobile and wireless technologies around the world has set up an unprecedented opportunity for global health delivery. The International Telecommunication Union estimates that total mobile cellular subscriptions reached almost 6 billion by the year 2012, corresponding to a global penetration of $86 \%$ [8], with more than $70 \%$ of them residing in developing countries. Mobile phone networks cover at least $90 \%$ of the world's population, including over $80 \%$ of those living in rural areas [9].

Mobile health, now commonly referred to as mHealth capitalizes on the successes of the mobile telephony to deliver health information and care in an efficient and improved manner. This paper highlights the prospects for mHealth in Pakistan and other developing countries of the region. The rest of the paper is organized as follows: Sections 2 and 3 illustrate the ICT growth and healthcare facilities in the region respectively. Section 4 presents a detailed discussion on mHealth, its conceptual model, applications and projects. Section 5 highlights the future steps needed to be undertaken to make mHealth benefits far reaching. Concluding remarks are provided in Section 6 which is followed by references.

\section{ICT Growth in Developing Countries}

Information and Communication Technologies have served as perfect accelerator for social, economic and Industrial progress. The speed at which ICT is diffusing in the society has taken everybody by surprise. More interesting is the fact that developing countries have left the developed countries behind in terms of the increase in use of communications such as the mobile telephone subscriptions. Figures 1-4 show the ICT services subscriptions [8,10-12] in the developing countries of South East Asian region.

This surge in the usage of internet, broadband, mobile phones, smart phones and related technologies can be effectively used to provide health services at a low cost.

The penetration can also help the health care services in reaching the remote areas where such facilities, infrastructure and services are patchy [13].

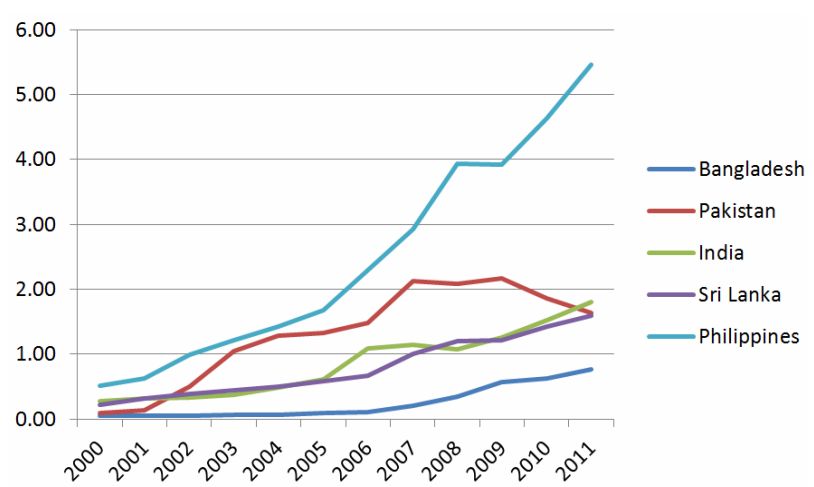

Figure 1. Fixed wired internet subscriptions per 100 inhabitants.

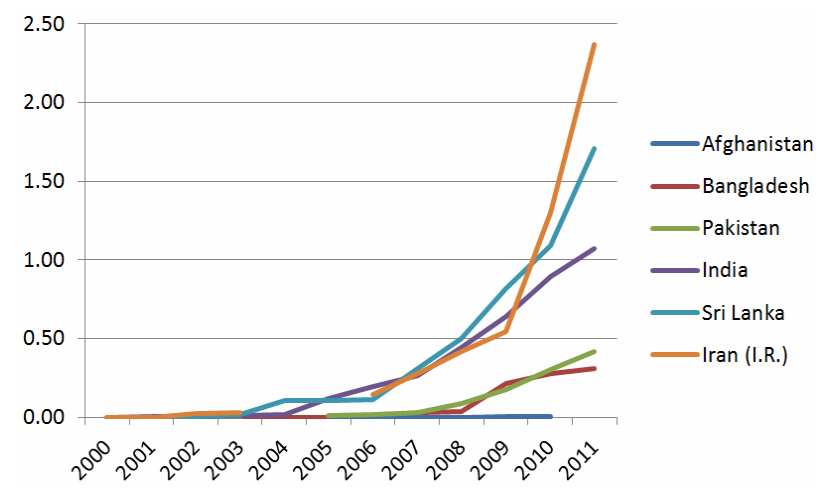

Figure 2. Fixed wired broadband subscriptions per 100 inhabitants.

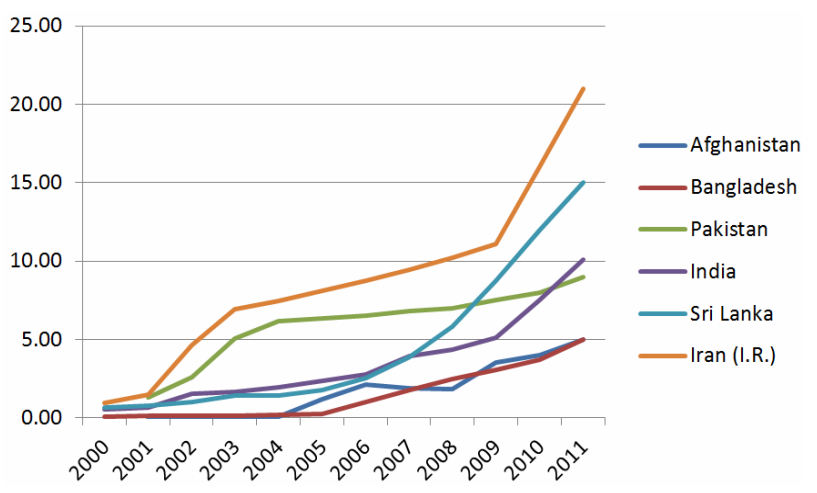

Figure 3. Percentage of Individuals using the Internet.

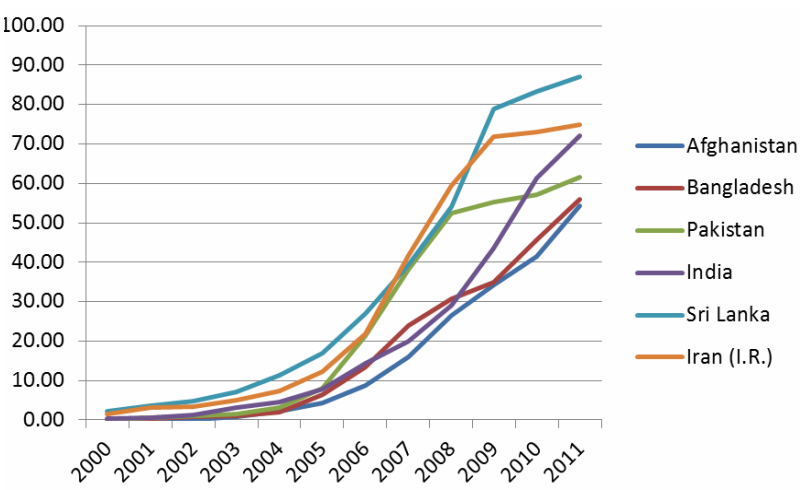

Figure 4. Mobile cellular subscriptions per 100 inhabitants.

\section{Health Care Facilities in Pakistan}

Many developing countries have inadequate health care services and suffer from a dearth of doctors and other trained health care professionals. The inappropriate distribution of doctors, scratchy infrastructure of health care facilities, roads and transport make it even more difficult to provide health care in remote and rural areas. Moreover, where clinics and hospitals exist, they are often illequipped or beyond reach [14]. Figures 5 and 6 show the statistics pertaining to the physician density and hospital beds in developing countries of the region. Pakistan 
being a developing country lack even basic health care infrastructure. A brief summary of the core health indicators in the country is shown in Tables $\mathbf{1}$ and $\mathbf{2}$.

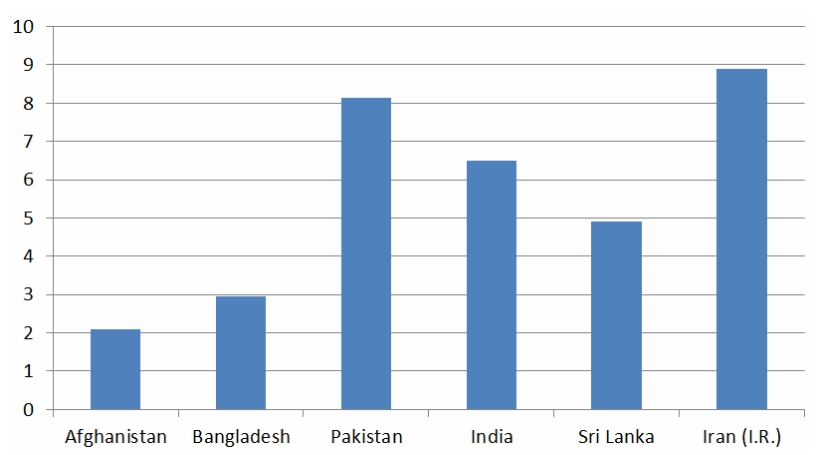

Figure 5. Physician density per 10, 000 population [15].

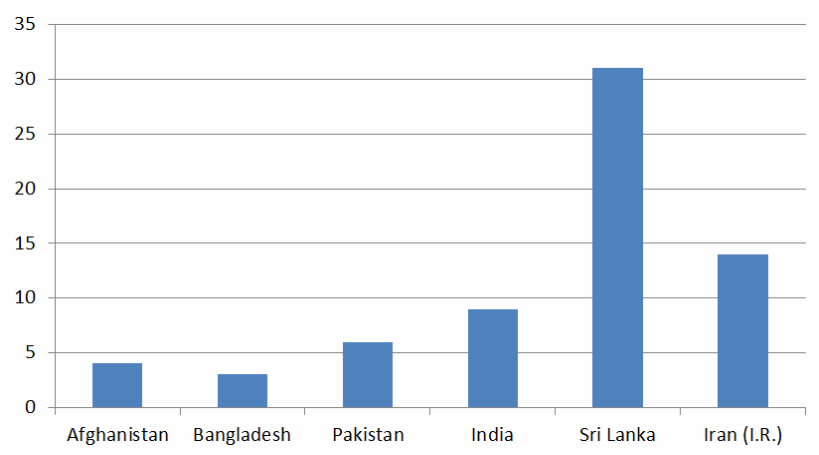

Figure 6. Hospital beds per 10, 000 population [15].

Table 1. Heath service facilities in Pakistan (2011-12) [16].

\begin{tabular}{lcc}
\hline \multicolumn{1}{c}{ Facility } & Quantity & Population/Facility \\
\hline Hospitals & 972 & $185,235 / \mathrm{Hosp}$ \\
Dispensaries & 4842 & $37,185 / \mathrm{Disp}$. \\
Basic Health Units & 5374 & $33,504 / \mathrm{BHU}$ \\
Maternity Child Health Center & 909 & $198,073 / \mathrm{MCHC}$ \\
TB Centers & 304 & $592,264 / \mathrm{TBC}$ \\
First Aid Centers & 1080 & $166,711 / \mathrm{FAC}$ \\
Beds in Hospitals & 108137 & $1,665 / \mathrm{Bed}$ \\
\hline
\end{tabular}

Table 2. Registered Human Resources in Pakistan (2011-12) [16].

\begin{tabular}{lcc}
\hline \multicolumn{1}{c}{ Human Resource } & Quantity & Population/HR \\
\hline Doctors & 149201 & $1,207 / \mathrm{Dr}$. \\
Specialists & 19623 & $9,175 / \mathrm{Sp} . \mathrm{Dr}$. \\
Dentists & 10958 & $16,431 / \mathrm{Dentist}$ \\
Dental Specialist & 433 & $415,815 / \mathrm{D} . \mathrm{Sp}$. \\
Nurses & 76244 & $2,361 / \mathrm{Nurse}$ \\
Midwives & 27153 & $6,631 / \mathrm{MW}$ \\
Lady Health Visitors & 11510 & $15,643 / \mathrm{LHV}$ \\
\hline
\end{tabular}

\section{4. mHealth}

The advancements in ICT and related services have paved way for availability of cost effective facilities to the people around the globe [17]. As already pointed out, the accelerated penetration of electronic devices into new markets has fuelled interest in eHealth, i.e. the storage, transmission, and retrieval of digital data using electronic means to support health care at local and distant sites [18]. The use of wireless technologies with eHealth services is termed as mHealth. In general terms, mHealth is the application of mobile computing, medical sensors, and communication technologies for healthcare. They are created as a synergy of emerging mobile medical computing, medical sensor technologies, and communication technologies [19].

Mobile technology promises a wide range of functions through the use of intelligent handsets called Smartphones. The functions include remote diagnostic monitoring, data collection, information dissemination, and public education and alerts systems [20]. Some key uses of smartphones are shown in Figure 7. Several platforms have been proposed to provide easy to use and cost effective solutions for remote patient doctor interaction over a cellular network [21,22]. Moreover, several specifications have been put forth to conceptualize patient data management for hospitals and other type of health care facilities [23-25].

MHealth has the potential to help developing countries combat many diseases. This includes communicable diseases such as tuberculosis. Messages and reminders can be sent to patients regarding their pills using mobile phones. Similarly, infant and maternal mortality can be reduced by delivering advice through SMS pregnant mothers and health information to community health workers [20].

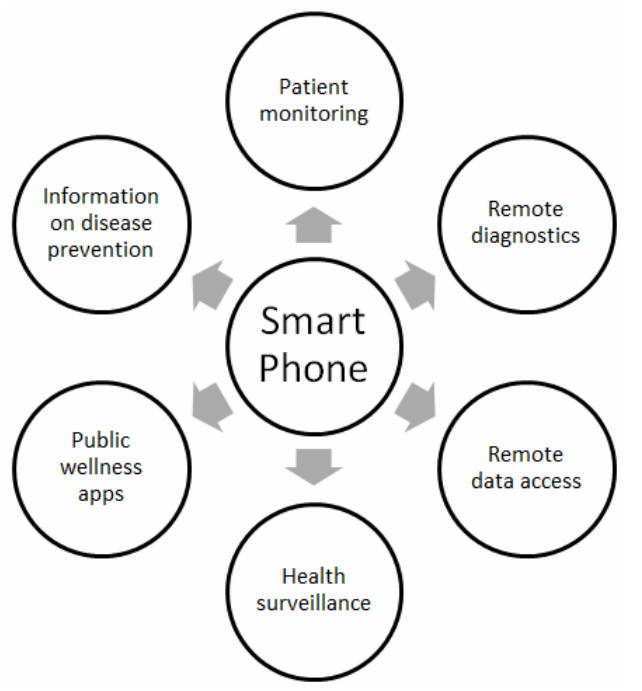

Figure 7. Mobile key to solving health challenges [20]. 


\subsection{Conceptual Model of mHealth System}

Figure 8 shows conceptual model of a mHealth system [17]. The model highlights that a mobile phone, laptop, or PDA can be used to connect to the health system through GSM network or Internet. Using the internet, the web portal of the health system can be accessed which can be used to access patient record database maintained at health care facility. On the other hand, GSM network may link a user with the $24 \times 7$ support center that can provide emergency medical response or medical advice using tele-triage mode.

These mHealth systems can be particularly beneficial in the areas that lack appropriate health care facilities and infrastructure. As indicated in earlier sections, such remote areas generally have access to ICT systems through a basic infrastructure. The availability these ICT facilities may be used to get medical advice from health care providers at remote locations through the support centers working round the clock.

These support centers have access to patient records as well as the health care providers and as a result, they can provide personalized health care advice to the patients.

\section{2. mHealth Beneficiaries and Advantages}

Many stakeholders can benefit from the advances in mHealth. These include individuals, government, health organizations, NGOs, employers, and suppliers. It has the potential to reduce per capita cost of healthcare while increasing or at least maintaining care quality.

Messages can enhance disease and epidemic awareness as well as the education of health service workers. All in all mHealth has a role to play in improving new "gross national happiness" indicators by producing a happier, healthier populace, and has the potential to transform health service delivery [20].

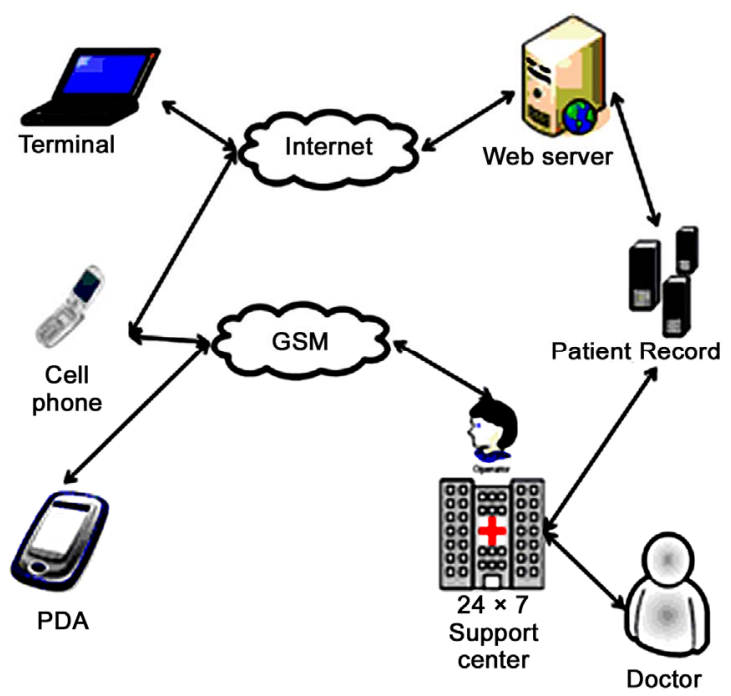

Figure 8. Conceptual model of mHealth System [17].

\section{3. mHealth Applications}

A number of mHealth applications are available in the market. Health service providers, whether public or private, are embracing the new technological solutions. An account of variety of such applications [9] follows:

\subsubsection{Diagnostic Support and Data Collection}

These tools help with disease surveillance, treatment as well as in collection of data for disease tracking. They are also used to collect and store patient data. Some examples include EpiSurveyor, ChildCount+, and Pesinet.

\subsubsection{Reminders on Treatment and Appointments}

These tools provide messages and reminders to the patient regarding treatment or appointments. WelTel, TxtAlert etc. are examples of such applications.

\subsubsection{Emergency Medical Response}

Call-in or SMS services are available to request ambulances or emergency response teams or personnel. Examples include the 1020 or 1021 helplines in Karachi, Pakistan.

\subsubsection{Health/Medical Call Centers}

These facilities provide access to medical advice, counseling, information using tele-triage mode. Telenor Teledoctor is an example of such application.

\subsubsection{Healthcare Supply Chain Management}

These tools help in tracking of medical goods in supply chains using mobile recording. Examples include Pedigree, PharmaSecure, and Stop Stock-outs.

\subsubsection{Health Information and Promotion}

These applications propagate text and voice messages to distribute health information to subscribers. The information may relate to epidemic, disease prevention, child care, maternal health etc. for instance, Texttochange, text4baby, and YoungAfricaLive.

\subsubsection{Training and Support for Healthcare Workers}

These are mobile device applications that are used to train, test, supervise, and support healthcare workers. They include FrontlineSMS, AMREF, and eMOCHA.

\subsubsection{Healthcare Payments and Insurance}

These are mobile device applications that link mobile money platforms to smart-cards, vouchers and insurance companies. Changamka and Arogya Raksha Yojana are such applications.

\section{4. mHealth Projects}

Many mHealth project case studies have been organized 
by a number of organizations throughout the world. These studies include application areas from least specialized (education and awareness) to most specialized (diagnostic and treatment support). Some of these are categorized here by their more specialized function. A detailed description of these projects is available in [26].

\subsubsection{Education and Awareness}

- Freedom HIV/AIDS Project, India

- $\quad$ Learning about Living, Nigeria

- Project Masiluleke, South Africa

- Text to Change (TTC)-HIV Prevention through SMS Quiz, Uganda

\subsubsection{Remote Data Collection \\ - Cell-PREVEN, Peru \\ - Dokoza System, South Africa \\ - $\quad$ EpiHandy, Uganda, Zambia, Burkina Faso \\ - $\quad$ Phones for Health, Rwanda}

\subsubsection{Remote Monitoring}

- Cell-Life Project, South Africa

- Colecta-PALM, Peru

- Virtual Health Pet, Brazil

\subsubsection{Training for Healthcare Workers}

- HealthLine, Pakistan

- Mobile HIV/AIDS Support, Uganda

- Uganda Health Information Network, Uganda

\subsubsection{Disease and Epidemic Outbreak Tracking}

- $\quad$ Alerta DISAMAR, Peru

- FrontlineSMS, Worldwide

- GATHER, Uganda

- Handhelds for Health, India

\subsubsection{Diagnostic and Treatment Support}

- Ericsson and Apollo Hospitals Initiative, India

- HIV Mobile Decision Support, South Africa

- Mobile E-IMCI, Tanzania

- Nacer, Peru

\section{Future Steps}

\subsection{Public-Private Partnerships}

Public-private partnerships have demonstrated to be the cornerstone of successful mHealth initiatives. Private sector has remarkable capacity to produce state-of-the-art solutions for public health challenges. Governments have access to existing infrastructure and networks, making them an essential entity in successful integration of mHealth frameworks into existing health systems. Furthermore, an active role must be taken in scaling up the existing pilot projects to full-fledged healthcare platforms [18].

\subsection{Health System Strengthening}

Although mobile telecommunication devices will ease the burden on limited health care resources, thus making them available to more people than ever before but in order to tap the real potential of mHealth projects, their access to those seeking benefit must be ensured. This can on only be achieved by strengthening the health systems. A user centric framework is crucial to the success of these initiatives [18].

\subsection{Adopt a Systematic Approach [9]}

A systematic approach is needed for exploring worthy opportunities and developing solutions. The approach must identify the real needs of the masses and design standards, platforms and models that address them. The approach should be tied to the national health strategy, in particular for developing healthcare human resources.

\subsection{Encouraging Developers and Innovations}

The variety of mHealth applications presented in earlier sections indicates that the impact of these applications has been significant. Hence, it is imperative that technological innovations to mobile phone products offer exciting new prospects for future mHealth projects, and developers must be encouraged to develop more innovative products [18].

\subsection{Aim for Scale [9]}

The goals for mHealth projects must be ambitious and the focus should be on quick deployment of the most promising innovations and emphasis must be laid on pilot projects that have the ability to be scaled quickly.

\subsection{Evaluations}

mHealth is an emerging field with little experience or guidance on evaluation frameworks for implementations. Therefore the initiatives must be synthesized and information must be shared to ensure the availability of diverse resources on various aspects of project design, implementation, and management. The availability of practical information on mHealth implementation and evaluation can dramatically accelerate and ease the adoption of mobile technologies by groups working in health care sector [18].

\section{Conclusions}

The field of mHealth is growing rapidly. It has proven to be beneficial through dozens of successfully implemented projects round the globe. Moreover, technological innovations will bring about enhanced benefits in the years to come. 
Health needs in developing countries have grown at alarming pace and now include chronic diseases to go with communicable diseases. mHealth is well positioned to counter these challenges using current trends in ICT. Emerging technologies will also be an asset in tackling health needs of today and tomorrow.

Careful thought must also be put in creating incentives that encourage all stake holders to contribute in the development of mHealth. The long-term goal underlying all these efforts must be to ensure that mHealth programs have a significant and lasting influence on level health care across the globe particularly in the developing countries.

\section{REFERENCES}

[1] Z. Ahmad, "mHealth: A Paradigm Shift in Delivery of Healthcare," PIMA Biennial Convention, 2012.

[2] A. Burney, N. Mahmood and Z. Abbas, "Information and Communication Technology in Healthcare Management Systems: Prospects for Developing Countries," International Journal of Computer Applications, Vol. 4, No. 2, 2010, pp. 27-32.

[3] R. Wootton, N. G. Patil, R. E. Scott and K. Ho, "Telehealth in the Developing World," Royal Society of Medicine Press, IDRC, 2009. ISBN 978-1-85315-784

[4] D. C. Alverson, L. R. Swinfen, L.P. Swinfen, K. Rheuban, C. Sable, A. C. Smith, et al., "Transforming Systems of Care for Children in the Global Community," Pediatric Annals Article on International Pediatric Telehealth, Vol. 38, No. 10, 2009, pp. 579-585.

[5] R. Wootton, "Telemedicine," British Medical Journal, Vol. 323, 2001, pp. 557-560. doi: $10.1136 /$ bmj. 323.7312 .557

[6] N. Ullah, P. Khan, N. Sultana and K. S. Kwak, "A Telemedicine Network Model for Health Applications in Pakistan: Current Status and Future Prospects," International Journal of Digital Content Technology and Its Applications, Vol. 3, No. 3, 2009, pp. 149-155.

[7] C. C. Missen and T. M. Cook, "Appropriate InformationCommunications Technologies for Developing Countries," World Health Organization Bulletin, Vol. 85, No. 4, 2007, p. 248.

[8] International Telecommunication Union (ITU), "Key Statistical Highlights: ITU Data Release June 2012," 2012. http://www.itu.int/ITU-D/ict/statistics/material/pdf/2011 $\% 20$ Statistical\%20highlights_June_2012.pdf

[9] "MHealth Education: Harnessing the Mobile Revolution to Bridge the Health Education \& Training Gap in Developing Countries," MHealthEd, Irish Global Health Education Innovation Institute (IHEED), June 2011. http://www.mobileactive.org/files/file_uploads/iheed_rep ort_updates.pdf

[10] UNCTAD, "Information Economy Report 2012: The Software Industry and Developing Countries," United Nations Publication.

http://unctad.org/en/PublicationsLibrary/ier2012_en.pdf
[11] UNCTAD, “Information Economy Report 2011: ICTs as an Enabler for Private Sector Development," United Nations Publication. http://unctad.org/en/PublicationsLibrary/ier2011_en.pdf

[12] UNCTAD, "Information Economy Report 2009: Trends and Outlook in Turbulent Times," United Nations Publication. http://www.unctad.org/en/docs/ier2009_en.pdf

[13] A. Burney, N. Mahmood, Z. Abbas and Z. Bashir, "Healthcare Management System and Information and Communication Technology: Prospects for Pakistan," First International eHealth Conference, AKUH Karachi, 2010.

[14] E. Z. A. Junejo, "SUPARCO Telemedicine Pilot Project." http://www.isnet.org.pk/downloadables/telemedicine_pap er.pdf

[15] World Health Organization (WHO), "Global Health Observatory Data Repository." http://apps.who.int/gho/data/node.main.475

[16] “Economic Survey 2011-12," Ministry of Finance, Government of Pakistan. http://www.finance.gov.pk/survey_1112.html

[17] N. Mahmood, A. Burney, Z. Abbas and K. Rizwan, "Data and Knowledge Management in Designing Healthcare Information Systems," International Journal of Computer Applications, Vol. 50, No. 2, 2012, pp. 34-39.

[18] "Interactive Research and Development," MHealth to Improve TB Care, Version 1.0, 2012. http://irdresearch.org/wp-content/uploads/2012/05/mHeal th-to-Improve-TB-Care.pdf

[19] R. S. H. Istepanian, E. Jovanov and Y. T. Zhang, "Guest Editorial Introduction to the Special Section on M-Health: Beyond Seamless Mobility and Global Wireless HealthCare Connectivity," IEEE Transactions on Information Technology in Biomedicine, Vol. 8, No. 4, 2004, pp. 405414. doi:10.1109/TITB.2004.840019

[20] The Boston Consulting Group \& Telenor Group, "The Socio-Economic Impact of Mobile Health,” April 2012.

[21] A. Holopainen, F. Galbiati and K. Takizawa, "Health Gateway Mobile Phone Technology Offers Easy-to-Use and Cost-Effective Telemedicine Services for Rural and Remote Areas," Journal of eHealth Technology and Application, Vol. 5, No. 3, 2008, pp. 261-266.

[22] E. Jovanov, A. Milenkovic, C. Otto and P. C. Groen, “A Wireless Body Area Network of Intelligent Motion Sensors for Computer Assisted Physical Rehabilitation," Journal of Neuro Engineering and Rehabilitation, Vol. 2, No. 6, 2005. doi:10.1186/1743-0003-2-6

[23] N. Mahmood and A. Burney, "Temporal and Fuzzy Relational Databases," Lambert Academic Publisher, Germany, 2011.

[24] A. Burney, N. Mahmood and Z. Abbas, "Advances in Fuzzy Rough Temporal Databases," Proceeding of 11th WSEAS International Conference on AIKED, University of Cambridge, 22-24 February 2012, pp. 237-242.

[25] A. Burney, Z. Abbas, N. Mahmood and Q. Arifeen, “Application of Fuzzy Rough Temporal approach in Patient Data Management (FRT-PDM)," International Journal of Computers, Vol.6, No. 3, 2012, pp. 149-157.

[26] UN Foundation, "mHealth for Development: The Opportunity of Mobile Technology for Healthcare in the Developing World," 2009.

http://unpan1.un.org/intradoc/groups/public/documents/u npan/unpan037268.pdf 